Supplementary Data

\title{
Engineering Polymer Forest on Membranes: Tuning Density, Thickness, and Architecture for Biofouling Control
}

\author{
ACS Applied Polymer Materials
}

September 02, 2020

Wen Ma, ${ }^{1}$ Liuqing Yang, ${ }^{1}$ Tiantian, Chen, ${ }^{1}$ Zhibin Ye, ${ }^{2}$ Nathalie Tufenkji, ${ }^{3}$ and Md. Saifur Rahaman ${ }^{1 *}$

${ }^{1}$ Department of Building, Civil and Environmental Engineering Concordia University, Montreal, QC, Canada H3G $1 M 8$

${ }^{2}$ Department of Chemical and Materials Engineering Concordia University, Montreal, Canada H3G 1 M8

${ }^{3}$ Department of Chemical Engineering, McGill University, Montreal, QC, Canada H3A 0C5

§Present Addresses

Department of Chemical and Environmental Engineering, Yale University, New Haven, CT, 06520, USA

*Corresponding author: Md. Saifur Rahaman

Email address: saifur.rahaman@,concordia.ca

Phone: 514-848-2424 Ext 5058. 


\section{Chemicals}

$\mathrm{N}$-(3-dimethylaminopropyl)-n'-ethylcarbodiimide hydrochloride (EDC), ethylenediamine (ED), n-hydroxysuccinimide (NHS), 4-(2-hydroxyethyl)-1-piperazineethanesulfonic acid (HEPES), 2-(n-morpholino)ethanesulfonic acid (MES), ethylenediaminetetraacetic acid (EDTA) ( $\geq 99 \%$ ), disodium phosphate $\left(\mathrm{Na}_{2} \mathrm{HPO}_{4}\right)$ (NIST SRM 2186II), potassium dihydrogen phosphate $\left(\mathrm{KH}_{2} \mathrm{PO}_{4}\right)$ (anhydrous, HPLC LiChropur ${ }^{\circledR}$ ), ammonium chloride $\left(\mathrm{NH}_{4} \mathrm{Cl}\right)(\geq 99.5 \%)$, magnesium sulphate $\left(\mathrm{MgSO}_{4}\right)(\geq 99.5 \%)$, and Luria Bertani (LB) (microbiologically tested) were purchased from MilliporeSigma (Oakville, ON, Canada). Isopropanol ( $\geq 99 \%$ ), calcium chloride $\left(\mathrm{CaCl}_{2}\right)$ (anhydrous, $\geq 96.0 \%$ ), sodium dodecyl sulfate (SDS) ( $\geq 98.5 \%$ ), methanol (peroxide-free/sequencing), hexane (Certified ACS), and sodium chloride $(\mathrm{NaCl})(\geq 99.5 \%)$ were purchased from Thermo Fisher Scientific ( $\mathrm{St}$ Laurent, QC, Canada).

\section{Characterization of membranes}

The water contact angle of membrane was measured by a video contact angle system (VCA, AST Products, Inc., Billerica, MA, USA). The average value obtained from at least six positions on each sample was report. The contact angle of the membrane with three different liquids: water, diiodomethane, and glycerol were measured, and the surface energy value was calculated with the system's SE-2500 software under the geometric theory model. The functional groups on the membrane surface were investigated via Fourier Transform Infrared (FT-IR) spectroscopy on a Nicolet 6700 / Smart iTR (Thermo Scientific, Waltham, MA, USA) equipped with an attenuated total reflectance single logic accessory (ATR). Membrane morphology was observed via a FEI Quanta 450 environmental scanning electron microscope (FE-ESEM) (FEI company, USA) after adding a platinum nanoparticle $(\sim 4 \mathrm{~nm})$ coating. Membrane topography was investigated using an atomic force microscope (AFM) (NanoINK Inc. Skokie, IL, USA) in tapping mode and the corresponding roughness was measured using the "Gwyddion" statistical software. The surface zeta potential of membrane was assessed by an electrokinetic analyzer (EKA) (Anton Paar, Graz, Austria) using $1 \mathrm{mM} \mathrm{KCl}$ solution, and the $\mathrm{pH}$ was adjusted by $1 \mathrm{M} \mathrm{NaOH}$ and $1 \mathrm{M} \mathrm{HCl}$. 


\section{Evaluation of membrane perm-selectivity}

A bench-scale cross flow filtration system was used to test water permeate flux and salt rejection (Figure S1). Specifically, a membrane with an effective area of $33 \mathrm{~cm}^{2}$ was compacted for 5-8 hr at 27.3 bar (400 psi) until a steady water flux was reached. The permeation flux was monitored with a digital flow meter (Liquid Flow Meter SLI-2000, Sensirion Inc. CA, USA) and salt rejection was assessed by measuring the rejection of 50 $\mathrm{mM} \mathrm{NaCl}$ solution using a calibrated conductivity meter (Oakton Instruments, Vernon Hills, IL, USA). All filtration experiments were performed at $20.0 \pm 0.5^{\circ} \mathrm{C}$ (maintained by a chiller) with a cross-flow rate of 0.5 litre per minute (LPM).

\section{Assessment of membrane antibiofouling performance via static contact}

Static antimicrobial tests were performed by comparing the quantity of bacterial colonies on different membranes after two hours contact with bacterial suspension (Escherichia coli (E.coli). The PGEN-GFP (LVA) ampR), also called plate counting method, was used. The bacterial suspension with an optical density (OD) of $\lambda_{600} \mathrm{~nm}=0.3 \pm 0.01$, as measured by UV/VIS spectrophotometry (UV/VIS Agilent Cary 8454 spectrophotometer, CA, USA), represents an E.coli concentration of $10^{7}-10^{8} \mathrm{CFU} / \mathrm{mL}$ and the detailed preparation protocol was described in our previous work. ${ }^{1,2}$

To conduct the test, $2 \mathrm{~mL}$ of bacterial suspension was injected in each well of a FalconTM polystyrene Millicell ${ }^{\circledR}$ 12-well plate (Thermo Fisher Scientific, Waltham, MA, USA), containing $3.8 \mathrm{~cm}^{2}$ membrane coupons fixed at the bottom with the modified side contacting the suspension. Then, the well plate was incubated at $35^{\circ} \mathrm{C}$ at $100 \mathrm{rpm}$ shaking for $2 \mathrm{~h}$. The bacterial suspension was discarded, and each well was refilled with $2 \mathrm{~mL} 0.9 \%$ $\mathrm{NaCl}$ followed by $5 \mathrm{~min}$ shaking at $100 \mathrm{rpm}$ to remove the loosely attached bacterial cells. The quantity of bacteria on membrane was quantified via plate counting method as described in previous work. ${ }^{1}$

The bacteria-adhesion and bacteria-inactivation performance of membrane were evaluated by observing the live/dead status of bacteria by confocal laser scanning microscopy (CLSM) (Nikon Eclipse TiE inverted C2 confocal microscope, Nikon Instruments Inc., NY, USA). 
E.coli (PGEN-GFP (LVA) ampR) and Bacillus subtilis (B. subtilis, ATCC6633) were used as model of gram negative (G-) and model of gram positive $(\mathrm{G}+)$ organism, respectively. Before observation, membrane coupons were dyed with green and red fluorescent nucleic acid stains. To prepare the stain solution, $100 \mu \mathrm{L}$ of SYTO 9 and propidium iodide (PI) (LIVE/DEAD ${ }^{\circledR}$ BacLight ${ }^{\mathrm{TM}}$ Bacterial Viability Kits L7012, Invitrogen Detection Technologies, MA, USA) were mixed thoroughly and were diluted at a 1:100 ratio with sterilized water. Then, $300 \mu \mathrm{L}$ of the prepared stain-solution was added on the $2 \mathrm{~h}$-bacteriacontacted membrane coupon $\left(3.8 \mathrm{~cm}^{2}\right)$. The strain process took place under dark for 20 min and the dyed membrane sample was washed with $1 \mathrm{~mL}$ of $0.9 \% \mathrm{NaCl}$ solution and loaded on a glass slide fixed with glycerol and a glass cover slip for observation using a TIRF $40 \times$ oil lens. SYTO ${ }^{\circledR} 9$ and PI dyes were excited with $488 \mathrm{~nm}$ argon and $561 \mathrm{~nm}$ diode-pumped solid-state lasers, respectively. At least 10 images were taken on each sample, and they were analysed using Fiji ImageJ software to calculate the number of the live (stained by STYO ${ }^{\circledR}$ 9, green color) and dead bacteria cells (stained by both $\mathrm{STYO}{ }^{\circledR}$ 9 and PI, red color).

The durability of membrane biofouling-resistance was evaluated by comparing the volume of bacterial cells grown on membranes after $48 \mathrm{~h}$ of culturing. Different from the $2 \mathrm{~h}$ contact-experiment in which bacterial suspension only consisted E.coli, the $48 \mathrm{~h}$ bacterial culturing applied carbon resources and multiple salts in suspension to promote the formation of biofilms on membrane surface. Bacterial suspension was prepared by inoculating stock solutions of E.coli (B. subtilis), LB, and multiple salt (concentrated salt stocks should be prepared separately to prevent the precipitation) to sterilized water. The final bacterial suspension consisted of E.coli $10^{5}-10^{6} \mathrm{CFU} / \mathrm{mL}, 0.1 \% \mathrm{LB}, 0.2 \mathrm{mM} \mathrm{KH}_{2} \mathrm{PO}_{4}$, $0.8 \mathrm{mM} \mathrm{NH}_{4} \mathrm{Cl}, 8 \mathrm{mM} \mathrm{NaCl}, 0.15 \mathrm{mM} \mathrm{MgSO}_{4}, 1.2 \mathrm{mM} \mathrm{Na}_{3} \mathrm{C}_{6} \mathrm{H}_{5} \mathrm{O}_{7}, 0.5 \mathrm{mM} \mathrm{NaHCO}_{3}$, and $0.2 \mathrm{mM} \mathrm{CaCl}_{2}$ according to a published article by Ben-Sasson et al. ${ }^{3}$ To conduct the experiment, $2 \mathrm{~mL}$ of the bacterial suspension was contacted with $3.8 \mathrm{~cm}^{2}$ membrane coupons and incubated at $35^{\circ} \mathrm{C}$ under $100 \mathrm{rpm}$ shaking for $48 \mathrm{~h}$. The membrane coupons were washed and prepared for CLSM observation as described above. Five images were taken of each sample and these were analysed using Imaris 8 software to calculate the volume of the live and dead bacteria cells. 


\section{Statistical Analysis}

The data was analyzed via the Student's t-test (Excel) assuming a two tailed and homoscedastic/heteroscedastic distribution (determined by the F-test, $\mathrm{p}<0.05$ ) to determine any statistically significant differences. $\mathrm{P}$ values of $<0.05$ were considered significant. 


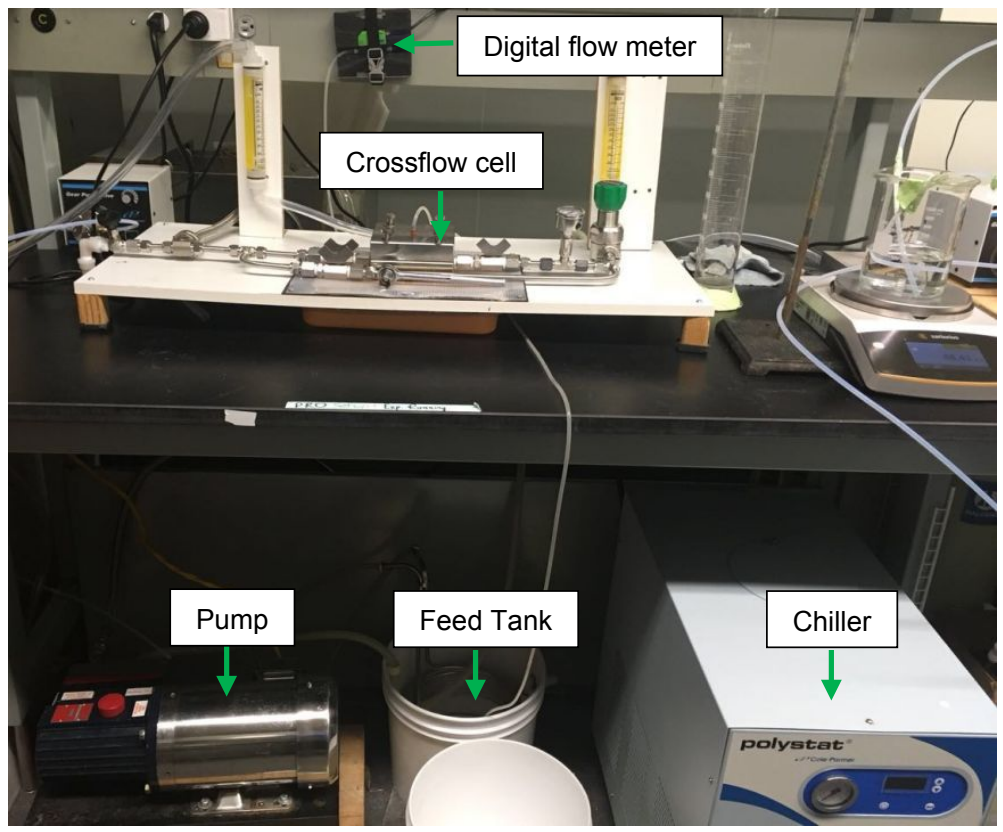

Figure S1. Image of the laboratory-scale RO cross flow filtration setup.

The setup consisted of a diaphragm pump (1.8 GPM, 230V, 60Hz, $3 \mathrm{PH}$ motor, Hydra cell, CA, USA), a stainless steel water permeation cell, a panel-mount flow meter $(0.25 \sim 1.5$ gpm, purchased from McMaster-CARR, Canada), a digital flow meter (Liquid Flow Meter SLI-2000, Sensirion Inc.CA,USA), and a 10 L feed solution tank. The whole system was connection by stainless and PVC tubes." 
Table S1. Elemental compositions (atomic percentage) of different membranes.

\begin{tabular}{|c|c|c|c|c|c|}
\hline Element & $P A$ & $M$ & $M-B r-5 \min$ & $M-B r-20 \min$ & $M-B r-60 \mathrm{~min}$ \\
\hline$O$ & $27.1 \%$ & $29.5 \%$ & $26.8 \%$ & $26.2 \%$ & $25.3 \%$ \\
\hline C & $68.8 \%$ & $57.5 \%$ & $69.1 \%$ & $68.5 \%$ & $69.2 \%$ \\
\hline$N$ & $4.1 \%$ & $4.8 \%$ & $1.3 \%$ & $1.8 \%$ & $1.5 \%$ \\
\hline$B r$ & $0 \%$ & $0 \%$ & $2.1 \%$ & $3.2 \%$ & $3.4 \%$ \\
\hline
\end{tabular}




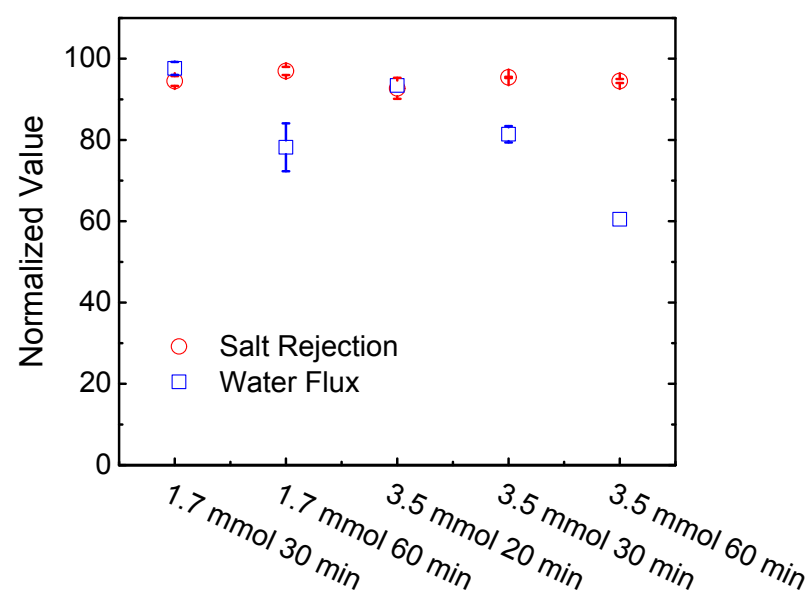

Figure S2. The water perm-selectivity of $M-B r$ membranes after PSBMA polymerization with varied initial concentration of monomers and polymerization time. 

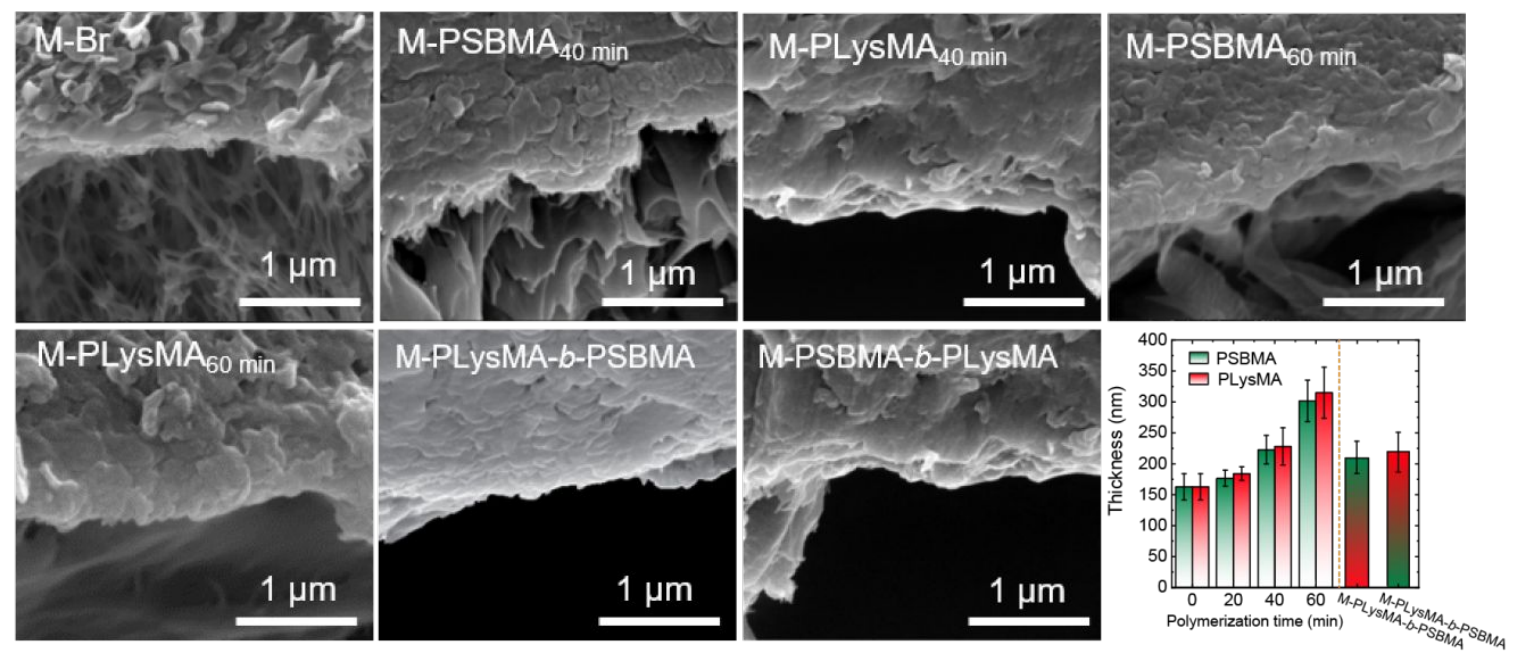

Figure S3. The thickness of polyamide layer before and after 3.5 mmol PSBMA and 1.7 mmol PLysMA modification. PSBMA- and PLysMA-block in copolymer brush are grafted by $20 \mathrm{~min}$, respectively. 

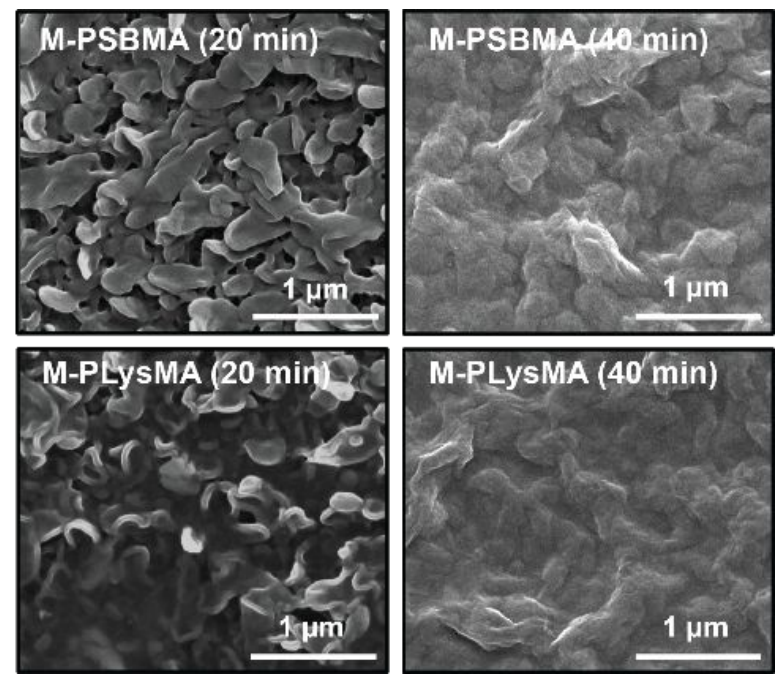

Figure S4. Surface morphology of membrane after $20 \mathrm{~min}$ and $40 \mathrm{~min}$ SMBA and PLysMA polymerization. 


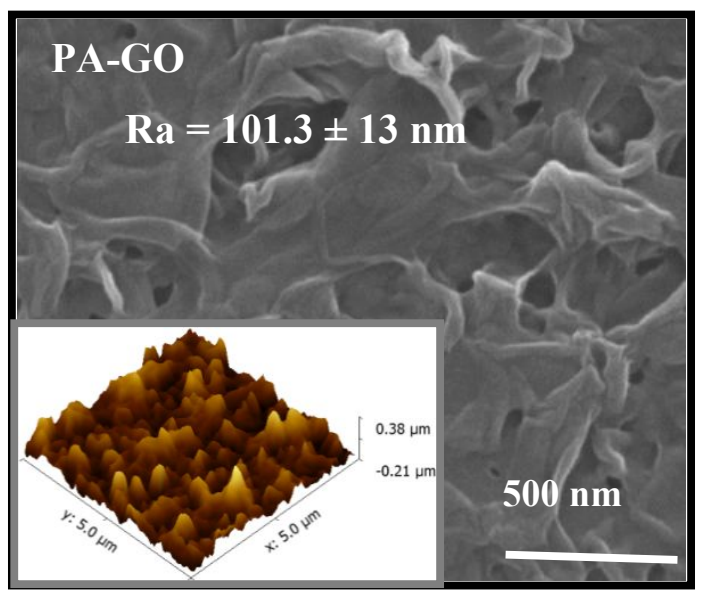

Figure S5. The AFM and SEM images of GO modified membrane. 

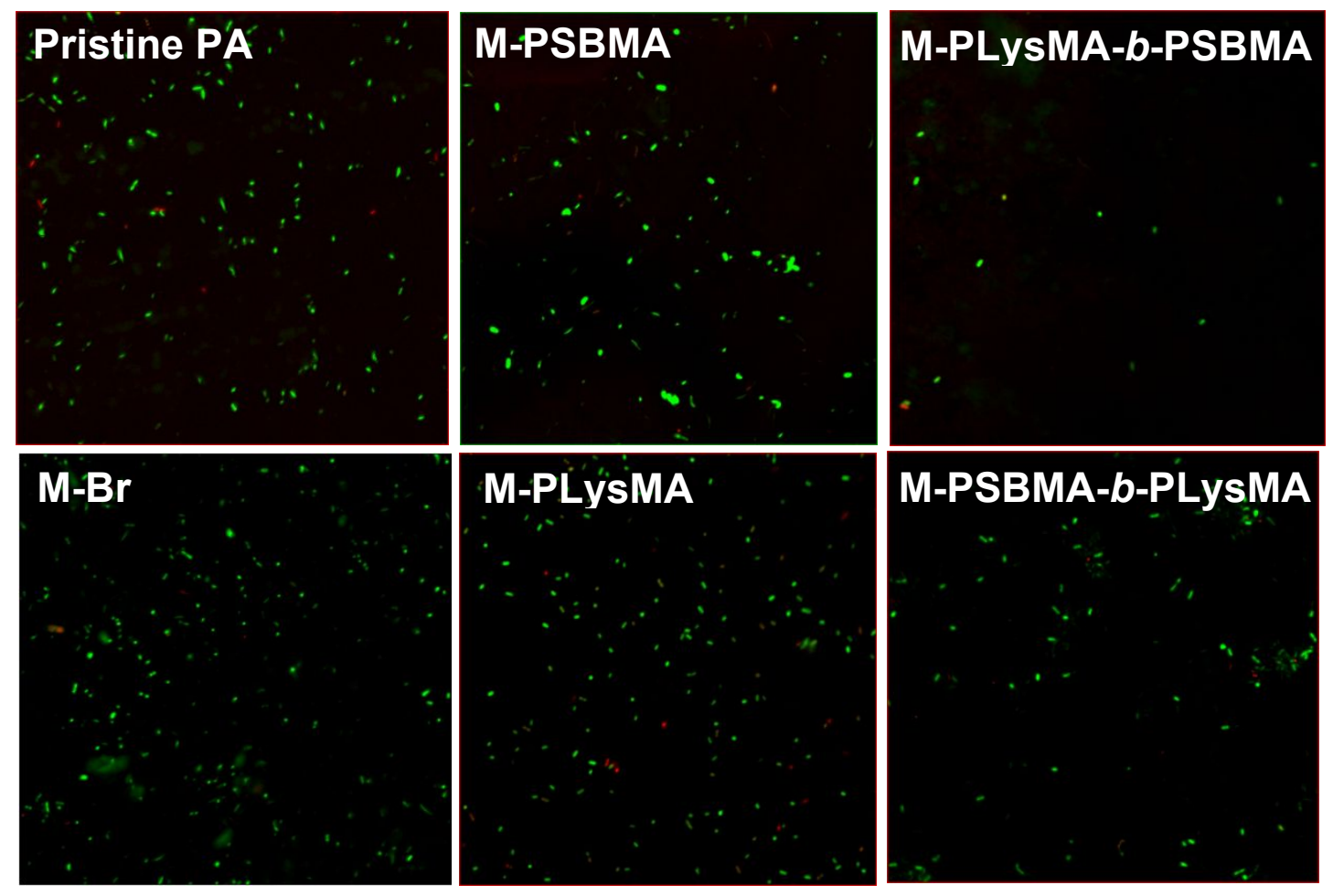

Figure S6. Representative confocal microscope images of E. coli on pristine and modified membranes after $2 \mathrm{~h}$ of static contact. The bacteria on the membrane surface were stained with PI (indicating dead cells, red color) and SYTO 9 (indicating live cells, green color) fluorescent nucleic acid stains before observation. Each image shows an area of 106 $\mu \mathrm{m} \times 106 \mu \mathrm{m}$. 


\section{Reference}

1. Ma, W.; Soroush, A.; Van Anh Luong, T.; Brennan, G.; Rahaman, M. S.; Asadishad, B.; Tufenkji, N., Spray- and spin-assisted layer-by-layer assembly of copper nanoparticles on thin-film composite reverse osmosis membrane for biofouling mitigation. Water. Res. 2016, 99, 188-199.

2. Ma, W.; Panecka, M.; Tufenkji, N.; Rahaman, M. S., Bacteriophage-based strategies for biofouling control in ultrafiltration: In situ biofouling mitigation, biocidal additives and biofilm cleanser. J. Colloid Interface Sci. 2018, 523, 254-265.

3. Ben-Sasson, M.; Lu, X.; Bar-Zeev, E.; Zodrow, K. R.; Nejati, S.; Qi, G.; Giannelis, E. P.; Elimelech, M., In situ formation of silver nanoparticles on thin-film composite reverse osmosis membranes for biofouling mitigation. Water Res. 2014, 62, 260-270. 